\title{
Comparing Jamaican Students' Performance with Students in the United States, the Grand Bahamas and the Online Program
}

Bahaudin Mujtaba, (Email: mujtaba@nova.edu), Nova Southeastern University

\begin{abstract}
Executive Summary:
This study documents learning and student performance through objective tests with graduate students in Kingston-Jamaica and compares the final exam results with students taking the same course, the same test, with the same instructor at different sites throughout the United States and in the Nassau cluster, Grand Bahamas. The scores are further compared with students who completed this course and final exam in the online format. The group of Jamaican, Bahamian and students in Tampa completing this course received traditional, face-to-face instruction in a classroom setting, with classes delivered in a weekend format with 32 face-to-face contact hours during the semester.
\end{abstract}

As expected, findings revealed that there was a statistically significant difference $(\%=.05)$ in the mean test scores of the pre-test and post-test for this group of students enrolled at the Kingston cluster. Furthermore, the results of final exam comparison with similar groups in the United States and Bahamas showed no significant differences. The comparison of student performance in Kingston with online students is also discussed. Overall, it is concluded that many of the learning outcomes designed to be achieved as a result of the course activities, specifically the final exam, were achieved consistently for students taking this course with the assigned faculty member in Jamaica, the United States and the Grand Bahamas.

\section{Distance Education in Jamaica and Learning Effectiveness}

$\mathrm{M}$ any international schools and universities have extended their offerings beyond their main campus and some have started clusters in the Caribbean countries, and Jamaica is one of the countries that many such institutions are attracted to because of the ever-increasing demand for higher education. For example, since 1984, Nova Southeastern University (NSU) has been offering classes in Jamaica, starting with the Ocho Rios cluster and later expanding to Kingston and Montego Bay. Students travel from across the length and breadth of the island to attend classes at these cluster sites. Today NSU has close to 800 active students in these cities. Interestingly, Jamaica with its small population had the highest enrollment in 2004, although NSU has been active in many countries including Bahamas, Trinidad, China, Brazil, France, Germany, Dominican Republic, England, Greece, Panama, and Venezuela. Some of the other international Universities facilitating distance education in Jamaica include Florida International University (US), Manchester Business College (England) and University of 
Dalhousie (Canada). Jamaicans are attracting diverse educational institutions because they want to be globally competitive and economically prosperous.

Jamaica is one of the many islands in the Caribbean with strong historical and cultural ties to both West Africa and Great Britain (Mujtaba et al, 2004). The population, almost three million, is a diverse blend of many different races with the majority being of African descent. The Jamaican culture, similar to others, is expressed through local stories, songs, dances, the use of herbs and bush medicine, local beliefs, the preparation of indigenous foods and through religious practices. Jamaicans perform folk songs and dance mainly during festivals and independence celebrations. During celebrations it is customary to wear their national costumes, called the Bandana. Jamaica's folk culture began mainly in the rural and mountainous villages. The main contributors to the Jamaican culture are the groups of people who made Jamaica their home. These contributors are the Africans, the English, The Spaniards, and the Indians. Jamaica, an island country, is the third largest island of the Greater Antilles of the West Indies and is situated south of Cuba. With its picturesque mountains and beautiful beaches, the island is known for its serene natural surroundings and is a popular tourist destination for many individuals throughout the world. Jamaica became a British colony in 1670. During the 18th century, planters began importing African slaves to work on the sugar plantations. Today the island's culture and customs blend its British and African roots. Jamaica gained its independence from Britain in 1962 and maintains a two-party political system. The island is named after the Native American word Xaymaca, meaning "isle of springs."

Over the centuries, there has been a variety of marriages of both different races and cultures, inevitably resulting in a fair tolerance of diversity. The advent of the information age, aided by the Worldwide Web and Cable Television, has exposed Jamaicans to various other cultures. One could assume that with the majority of Jamaicans being of African descent, as well as the British influence on their culture, Jamaicans would have very distinct ideas on social issues and education systems. And, they do, but in reality Jamaicans seem to take their cues from the outside world and no single culture has impacted the Jamaican people as much as that of North America. Jamaican attitudes tend to mirror American norms, beliefs and values more as the years progress (Mujtaba et al, 2004). It is expected that the education programs offered by American schools also mirror that of the United States' infrastructure. However, the differences between the British system, which has greatly impacted Jamaicans, and the United States educational systems cannot be disregarded. One major difference, with regard to the teaching faculty, that should be kept in mind is that the British tend to go deep into a few topics, while the United States educators tend to touch briefly on many topics. This difference in style may create some confusion for students, as students can overestimate the requirements of the course. This research attempts to study the learning outcomes achieved by Jamaican students, in Kingston, completing a graduate course with performance results of students in the United States and the Grand Bahamas.

Global trends toward the removal of cultural, geographic, social, and economic boundaries are providing education options and opportunities to individuals worldwide. The field of academia is fast catching up in this regard using cyberspace technology. Various forms of distance education, including the phenomenon of the virtual classroom and offsite campuses, are now being explored and developed. New challenges are presented by these developments, both for educational institutions and their stakeholders. As a developing country, Jamaica is challenged by various resource constraints. However, as global boundaries disappear, the country is still expected to compete against larger countries with greater resources. Therefore, innovative and cost effective methods have to be employed in the development of the country's human development. Nonetheless, distance education provides one opportunity for Jamaicans to compete effectively in the global marketplace. However, the quality of 
distance education courses must be equivalent as traditional courses if the graduates are to be successful on a global basis. Participants in this new era of distance education have many factors to consider including cross cultural challenges; the availability of the various infrastructural support systems; and hiring, training, compensating, and retaining the human resources needed to facilitate this development. Additionally, the needs of students, as well as the organizations that will be purchasing their skills must be considered in the development and facilitation of an education curriculum. Furthermore, the learning outcomes of students finishing their courses through distance education should be documented with students completing these courses in traditional formats.

Trends in delivery of today's graduate educations programs include distance education, electronic-based instruction, as well as traditional ground-based classes offered in weekend, daytime, and evening formats. Preziosi et al. (2000) state that "Today considerable attention is being paid to distance education.... and much of the interest in distance education is due to the increasing use of Internet-based instruction." Distance education has been the reality of life for many institutions and adult learners in the past few decades and it is becoming more widespread. There have been many evolutionary changes in distance education mainly brought on by technology and these changes have raised questions pertaining to learning effectiveness across various teaching formats. Researchers agree that much attention has been directed at the number of distance education offerings and delivery mechanisms among institutions as well as to questions of learning equivalency between course and program offerings through various sites and formats. Similarly, accrediting bodies have raised questions of equivalency that range from the resources provided to students in all modalities and the outcomes of student learning. As distance education both nationally and internationally increases in importance, continuous and documented evaluation will continue to be a critical component of process improvement. Of course, the schools offering distance education programs are held accountable for achieving the same level of effectiveness as alternative approaches available to students. Such accountability requires that institutions understand their stakeholders and their needs on a proactive basis in order to deliver superior value to them in today's new and demanding economy. One element of delivering superior value for educational institutions is to assess the achievement of learning outcomes among their students at various sites and to use such results for continuous improvement in order to always have a healthy learning environment for everyone (Mujtaba and Mujtaba, 2004).

The H. Wayne Huizenga School of Business and Entrepreneurship (Huizenga School) of Nova Southeastern University (NSU) has been offering undergraduate and graduate programs in the fields of business administration through various distance delivery modes for the past thirty years. One mode of distance delivery of education to adult students has been face-to-face instructor/student interaction in a classroom setting on four or five weekends in a given quarter while regularly exchanging assignments and feedback between faculty and students using electronic avenues. There are at least four different delivery methods (non-traditional offsite locations, traditional, online, and evening), and each format is expected to achieve the same outcomes. The Huizenga School has been testing each of its program's outcomes to ensure all programs demonstrate educational competencies that are comparable to those of traditional campus-based courses in Fort Lauderdale.

During the April-June 2004 quarter, Huizenga School's Masters Program offered "GMP5017 Delivering Superior Customer Value" course through traditional, face-to-face instruction at the Main Campus for full-time as well as part-time students; at off-campus locations on alternating weekends for working students; and, through online formats. This one section of the course under study offered in Kingston through the on-ground format was taught by an experienced instructor who has been regularly teaching this course in various formats. The faculty used a pre-test to assess everyone's current knowledge during the first session of the class and eventually used the same questions on the final exam to see how much improvement can be seen as a result of the learning activities during the semester. Classes met four different weekends during the 
term at hotels in Kingston, Jamaica. The class met about every three weeks during the term on Saturdays and Sundays from about 1:00-5:00 PM for four hours each day. The classes started one hour later on Saturdays and accordingly ended one hour later to accommodate students that were traveling from outside of Kingston. Students met many other times at various locations to complete their group assignments. The average time spent face-to-face outside of the class for group activities was reported to be nine hours. Some groups met more often in the face-to-face format while others were able to use technology to reduce face-to-face interactions since students lived at various sites throughout the Island.

There were a total of 38 students enrolled in "GMP5017-Delivering Superior Customer Value" class to obtain masters degrees. While a few of the students were about to finish the masters program, about $90 \%$ of them were totally new to the graduate program and this was their first semester. With regards to gender distribution, there were 8 males $(21 \%$ of the class) and 30 females $(79 \%)$ in the class. In the Islands, such low ratios of male to female student distribution in the graduate program are not unusual. As a matter of fact, some classes of 20 or more students taught by the author have included no male students. The average age, based on faculty observation and estimation, was about 27 years for this group. All of the students were working adults, some being school teachers while others were working as administrators or employees in the banking industry, government, private or pubic sector's tourismrelated jobs. This group showed great interest in the topics of this class as they all understood the importance of delivering value to customers in today's competitive global world of business.

\section{Course Description and Learning Objectives}

This course stressed the service aspects of an organization, especially customer service, marketing and organizational responsiveness, and how to create superior customer value. With an integrated marketing and operations perspective and the use of case analysis, students understand how to blend the delivery of service and quality, together with pricing strategies (as well as image, innovation, and intangibles) to maximize the value proposition. Strategies for optimizing and communicating customer value, measuring customer orientation, and relationship/retention marketing were also examined.

As stated in the course syllabus, students were expected to meet the exist competencies at the end of the courses based on the completion of the required readings and activities as determined by the Chairs and lead faculty members. Upon completion of this course, the student is expected to be able to:

1. Explain what is meant by customer orientation and responsiveness,

2. Understand the concept of customer value and how it impacts business decision-making.

3. Discuss how the various components of customer value (quality, service, pricing, and image) interact to build customer satisfaction.

4. Use operations and logistics processes to improve the delivery, monitoring, and measurement of customer services.

5. Consider the impact of quality on the value of an organization's offering and how quality can be improved.

6. Understand how pricing contributes to perceived customer value.

7. Examine how the relationship marketing paradigm creates long-term customer value.

8. Demonstrate a mature level of communication skills, especially the ability to present and defend positions; which is predicated on a sound value/values-based, customer-driven decision-making framework which responds to the business challenges of complex, competitive, and changing global markets. 
The book used for the class was titled "Designing \& Delivering Superior Customer Value: Concepts, Cases \& Applications" authored by Dr. Art Weinstein and Dr. Bill Johnson in 1999. Students thought the textbook was very timely and very relevant in terms of applicability for their places of employment. They seemed to enjoy the exercises, case studies and the application of the "Customer Value Action Items" to their current departments and customer base. Additional material was also distributed in class by the faculty. To keep up with current material on the topic, students were encouraged to review at least one relevant website each week and at least one newspaper or journal article to see how firms are delivering value to their customers.

\section{Course Assignments and Learning Outcomes}

The students were required to read the textbook, current event articles brought to the class by the faculty or students, and to conduct research for their individual and team projects. Oral parts of assignments required students to prepare a detailed presentation for the class. This was purposely designed this way so their colleagues can benefit from their thoughts and individual research. The following table (Table 1) represents a summary of the activities required for this course.

Table 1: Course Assignments for Submission

\begin{tabular}{|c|c|c|c|c|}
\hline Assignments Topics & Points & $\begin{array}{l}\text { Delivery } \\
\text { Method }\end{array}$ & $\begin{array}{l}\text { Due } \\
\text { Date }\end{array}$ & $\begin{array}{l}\text { Achieves Learning } \\
\text { Objectives Number }\end{array}$ \\
\hline Chapter Application. (In-class) & & Group & Session 1 & $1,2,3,4,5,6,7, \& 8$ \\
\hline $\begin{array}{l}\text { Value Propositions and Quality. (In- } \\
\text { class discussion) }\end{array}$ & & Group & Session 2 & $1,2,3, \& 8$ \\
\hline $\begin{array}{l}\text { Customer Value Action Items - select a } \\
\text { chapter. (Individual) }\end{array}$ & $10 \%$ & Written & Session 3 & $1,2,3,4,5,6,7, \& 8$ \\
\hline First Case Analysis - (group) & $20 \%$ & $\begin{array}{l}\text { Written \& } \\
\text { Oral }\end{array}$ & Session 4 & $3,4,5, \& 8$ \\
\hline Second Case Analysis -(Individual) & $10 \%$ & Written & Session 6 & $3,4,5, \& 8$ \\
\hline $\begin{array}{l}\text { Applied Customer Value Term Project } \\
\text { - (Group) } \\
\text { - Customer Service Philosophy } \\
\text { Booklet (Group) } \\
\end{array}$ & $35 \%$ & Mixed & $\begin{array}{l}\text { Session } 7 \\
\& 8\end{array}$ & $1,2,3,4,5,6,7, \& 8$ \\
\hline Final Exam (Individual)- & $10 \%$ & Written - & Session 8 & $1,2,3,4,5,6,7, \& 8$ \\
\hline $\begin{array}{l}\text { Participation - Includes answers to all } \\
\text { the "Customer Value Application" } \\
\text { exercises and other topics. }\end{array}$ & $15 \%$ & \multirow{2}{*}{\multicolumn{3}{|c|}{ * Two Quizzes offered as part of the participation points. }} \\
\hline Total: & $100 \%$ & & & \\
\hline
\end{tabular}

There was a total of four weekends during the term that the class formally met face-to-face for four hours each of the eight sessions. The assignments were distributed evenly throughout the term so the learning outcomes of the course are achieved progressively and reinforced many times over the semester for long-term retention. Even the final exam was used to reinforce learning one last time. Students were required to complete their final exam by marking the right choices and recording their answers on separate answer sheets. They were required to write their names on both the exam and the answer sheet. Once students completed their final exam and recoded all of their answers on the answer sheet, the answer sheets were collected for confidential grading by the faculty. Then, the students and faculty member as a class went over the questions and answers so the students could clarify their understanding if they did not get the answers right thus, hopefully, leading to better learning and long-term retention as a result of the reinforcement. In the mean time, students could actually see their own exam results right after its 
completion. The actual final exams were also collected from students as to keep it out of the hands of prospective students taking the class.

\section{Methodology and Results}

The purposes of this study were to document learning and to determine the significance of the results for objective pre-test and post-test exams when the group received traditional, face-to-face instruction in a classroom setting, with classes delivered in a weekend format. The faculty used a pre-test to assess everyone's current knowledge during the first session of the class and eventually used the same questions on the final exam to see how much improvement could be seen as a result of the activities taking place during the semester. Another intention for the study was to compare the learning with students in other locations and sites. The instrument used to measure student performance was an examination consisting of a combination of standardized "multiple-choice" as well as true and false questions, for which a total of 100 points were available. Specifically, the examination included 16 multiple-choice items, 24 true and false questions and two essay questions. It was assumed that the objective questions were equal in their level of difficulty. Also, students were allotted one hour to complete their exams.

\section{Research Questions: Hypothesis}

The research question for this study was as follows: Is there a statistically significant difference in the performance of students in the pre-test and post-test examination and their final examination scores compared to students in other sites in the course titled "Delivering Superior Customer Value"?

Null Hypothesis (Ho) I: Pre-test and post-test exam scores for Kingston students in GMP5017 will be similar.

Null Hypothesis (Ho) II: Final exam (post-test) scores for Kingston students in GMP5017 will be similar to the final exam scores of students in Florida and Bahamas.

\section{Results and Statistical Comparisons}

The pre-test was administered on the first session of the class and students were told that they can earn up to four bonus points on this pre-assessment test for a score of 90 or above, three bonus points for a score of 80 or above, two bonus points for a score of 70 or above, and one bonus point for a score of 60 or more points. The bonus points encouraged students to take the pre-assessment test seriously and they were able to complete it in less than 40 minutes. Many of the students were able to earn bonus points which were used as part of their final course grade. So, if a student had a total average of $89 \%$ (B plus) by the end of the semester and had earned two bonus points on the pre-test, then this student's final course grade would be an "A minus" according to the scale provided on the syllabus. There were a total of 37 usable data points for comparison of the pre- and post tests. The pre-test results show that the mean score for the group's pre-test was 73.4 out of 100 and the group's post-test score mean was 86.73 out of 100 possible points. 


\begin{tabular}{|l|r|r|}
\hline \multicolumn{3}{|c|}{ Table 2: t-Test: Paired Two Sample for Means or Pre- \& Post Tests } \\
\hline & \multicolumn{1}{l|}{ Pre-Test } & \multicolumn{1}{c|}{ Post-Test } \\
\hline Mean & 73.40540541 & 86.72972973 \\
\hline Variance & 83.52552553 & 35.48048048 \\
\hline Observations & 37 & 37 \\
\hline Pearson Correlation & 0.409257628 & \\
\hline Hypothesized Mean Difference & 0 & \\
\hline df & 36 & \\
\hline $\mathrm{t}$ Stat & -9.393363987 & \\
\hline $\mathrm{P}(\mathrm{T}<=\mathrm{t})$ one-tail & $1.6089 \mathrm{E}-11$ & \\
\hline $\mathrm{t}$ Critical one-tail & 1.688297289 & \\
\hline $\mathrm{P}(\mathrm{T}<=\mathrm{t})$ two-tail & $3.2178 \mathrm{E}-11$ & \\
\hline $\mathrm{t}$ Critical two-tail & 2.02809133 & \\
\hline
\end{tabular}

Students were allotted one hour for the post-test (final exam) and they were able to complete it during the allotted time. As can be seen from Table 2, the $t$ test statistics follows a $t$ distribution with 36 (37-1) degrees of freedom. The test is done at $\mathrm{a}=0.05$ level of significance and as such the rejection area is divided into the two tails for this two tail test, i.e. two equal parts of 0.025 each. The critical values for this two-tail test are +2.02809133 and -2.02809133 . As such, one would be able to reject the first null hypothesis if $t$ with 36 degrees of freedom is greater than +2.02809133 or smaller than -2.02809133 . The gain from pre-test to post-test score was 13 points which according to the analysis of paired t-test (Table 2 ) is statistically significant. Using a 0.05 level of significance, the null hypothesis (Ho) is rejected because $t=-9.393363987$ is smaller than the critical value of -2.02809133 . Also, because the $p$-value is less than alpha $(\alpha)=0.05$, there is sufficient evidence to reject the null hypothesis. Therefore, Null Hypothesis I (Ho) cannot be accepted since the scores are not similar. One can conclude that the post-test (final) exam scores are different from the pre-test score. Based on these results, the pre-test exam scores appear to be significantly lower than the post-test (final) exam scores. So, one can summarize that many of the learning outcomes designed to be achieved as a result of the course activities for GMP5017 in Kingston during the summer 2004 term were achieved due to the significant gain on the post-test examination.

The final exam scores of students in Kingston-Jamaica were compared with the final scores of students who took this class with the same faculty using the same final exam in Nassau-Bahamas in 2003 (as presented in Table 3). Comparing the results of students in Kingston with students in Nassau does not produce any statistically significant results because the p-value is greater than alpha $(\alpha)=0.05$ and the ttest value of 0.217527684 falls within the critical values of +2.004881026 and -2.004881026 . As such, Null Hypothesis II cannot be rejected which means that the final exam scores for Kingston students in GMP5017 are similar to the final exam scores of students in the Bahamas. 
Table 3: $t$ Test for Differences in Two Means for Final Exam:

Kingston Vs. Bahamas

\begin{tabular}{|c|c|}
\hline \\
\hline Data & \\
\hline Hypothesized Difference & 0 \\
\hline Level of Significance & 0.05 \\
\hline \multicolumn{2}{|l|}{ Population 1 Sample - Kingston } \\
\hline Sample Size & 38 \\
\hline Sample Mean & 86.73 \\
\hline Sample Standard Deviation & 5.96 \\
\hline \multicolumn{2}{|l|}{ Population 2 Sample - Bahamas } \\
\hline Sample Size & 18 \\
\hline Sample Mean & 87.11 \\
\hline Sample Standard Deviation & 6.41 \\
\hline \multicolumn{2}{|c|}{ Intermediate Calculations } \\
\hline Population 1 Sample Degrees of Freedom & 37 \\
\hline Population 2 Sample Degrees of Freedom & 17 \\
\hline Total Degrees of Freedom & 54 \\
\hline Pooled Variance & 37.27401667 \\
\hline Difference in Sample Means & -0.38 \\
\hline$t$-Test Statistic & -0.217527684 \\
\hline \multicolumn{2}{|l|}{ Two-Tailed Test } \\
\hline Lower Critical Value & -2.004881026 \\
\hline Upper Critical Value & 2.004881026 \\
\hline$p$-Value & 0.828616996 \\
\hline
\end{tabular}

The final exam scores of students in Kingston-Jamaica were further compared with the final scores of students who took this class with the same faculty using the same final exam in Tampa, Florida, in 2002 (as presented in Table 4). Comparing the results of students in Kingston with students in Tampa does not produce any statistically significant results because the p-value $(0.270888514)$ is greater than alpha $(\alpha)=0.05$ and the t-test value of -1.112001875 falls within the critical values of +2.003239388 and -2.003239388. As such, once again, Null Hypothesis II cannot be rejected which means that the final exam scores for Kingston students in GMP5017 are similar to the final exam scores of students in Tampa. 
Table 4: $t$ Test for Differences in Two Means for Final Exam:

Kingston Vs. Tampa

\begin{tabular}{|c|c|}
\hline Data & \\
\hline Hypothesized Difference & 0 \\
\hline Level of Significance & 0.05 \\
\hline \multicolumn{2}{|l|}{ Population 1 Sample - Kingston } \\
\hline Sample Size & 37 \\
\hline Sample Mean & 86.73 \\
\hline Sample Standard Deviation & 5.96 \\
\hline \multicolumn{2}{|l|}{ Population 2 Sample - Tampa } \\
\hline Sample Size & 21 \\
\hline Sample Mean & 88.68 \\
\hline Sample Standard Deviation & 7.17 \\
\hline \multicolumn{2}{|c|}{ Intermediate Calculations } \\
\hline Population 1 Sample Degrees of Freedom & 36 \\
\hline Population 2 Sample Degrees of Freedom & 20 \\
\hline Total Degrees of Freedom & 56 \\
\hline Pooled Variance & 41.19563571 \\
\hline Difference in Sample Means & -1.95 \\
\hline$t$-Test Statistic & -1.112001875 \\
\hline \multicolumn{2}{|l|}{ Two-Tailed Test } \\
\hline Lower Critical Value & -2.003239388 \\
\hline Upper Critical Value & 2.003239388 \\
\hline$p$-Value & 0.270888514 \\
\hline Do not reject the null hypothesis & \\
\hline
\end{tabular}

Last but not least, the final exam scores of students in Kingston-Jamaica were also compared with the final exam scores of students who took this class with the same faculty using the same final exam in the Online format using e-University platform in 2003 (as shown in Table 5). Similar to the results of the Bahamian and the group Tampa, comparing the results of students in Kingston with students in Online modality did not produce any statistically significant results because the p-value $(0.07718)$ is greater than alpha $(\alpha)=0.05$ and the t-test value of 1.8017 falls within the critical values of +2.00488 and -2.00488 . As such, once again, Null Hypothesis II cannot be rejected because the final exam scores for Kingston students in GMP5017 are similar to the final exam scores of students who completed this class in the online format.

Based on the data from the pre- and post-test exam scores, there appears to be sufficient data to state that there was a significant learning gain for students taking GMP5017 in Kingston during the summer 2004 term. Furthermore, the final exam scores of students in Kingston-Jamaica compared to the final scores of students who took this class and exam with the same faculty at the Nassau (2003) and Tampa (2002) clusters were similar. Furthermore, results show that students Kingston performed just as well as students who completed this class in the online format during 2003. This supports the second hypothesis that the final exam scores (student performance) for Kingston students in GMP5017 are similar to the final exam scores (student performance) of students in other locations, such as Tampa and Nassau, when the class is taught by the same faculty member. 
Like many other studies, this research had limitations and assumptions that were taken into consideration. It was assumed that the examination scores represented interval data. In addition, the assumptions were made that the instrument was valid and that there were no significant, systematic differences between the tests results (other than actual increased learning as a result of completing the activities and assignments during the term) to which study results may be attributed. The small sample size in Nassau and Tampa is a limitation impacting inferences that may be drawn from results of the study. Applicability of the result of this study is anticipated to be limited for groups included in this research to documentation of learning for some of the course objectives in the sections taught by this faculty.

Table 5: $\mathrm{t}$ Test for Differences in Two Means: Kingston Vs. Online

\begin{tabular}{|c|c|}
\hline Data & \\
\hline Hypothesized Difference & 0 \\
\hline Level of Significance & 0.05 \\
\hline \multicolumn{2}{|l|}{ Population 1 - Kingston } \\
\hline Sample Size & 38 \\
\hline Sample Mean & 86.73 \\
\hline Sample Standard Deviation & 5.96 \\
\hline \multicolumn{2}{|l|}{ Population 2 - Online } \\
\hline Sample Size & 18 \\
\hline Sample Mean & 83.43 \\
\hline Sample Standard Deviation & 7.27 \\
\hline \multicolumn{2}{|c|}{ Intermediate Calculations } \\
\hline Population 1 Sample Degrees of Freedom & 37 \\
\hline Population 2 Sample Degrees of Freedom & 17 \\
\hline Total Degrees of Freedom & 54 \\
\hline Pooled Variance & 40.97775 \\
\hline Difference in Sample Means & 3.3 \\
\hline$t$-Test Statistic & 1.801664507 \\
\hline \multicolumn{2}{|l|}{$\begin{array}{r}\text { Two-Tailed Test } \\
\end{array}$} \\
\hline Lower Critical Value & -2.004881026 \\
\hline Upper Critical Value & 2.004881026 \\
\hline$p$-Value & 0.077181851 \\
\hline Do not reject the null hypothesis & \\
\hline
\end{tabular}

\section{Conclusion}

The increasing interest and pressure by various educational stakeholders in the quality of education has fostered concern among accrediting bodies, as well as the institutions they accredit, in schools demonstrating comparable learning outcomes on the competencies acquired by graduates. This study attempted to demonstrate outcome equivalency in one section of this course while comparing the results to students who took this course with the same faculty in Tampa and Nassau clusters as well as those who completed it in the online format. The faculty member teaching this course, author of the study, has taught adults in Jamaica, Bahamas, Brazil, and the United States for nearly a decade and is multicultural since he was born in Afghanistan and temporarily lived in Pakistan as well. Since all the sections of this course, for comparison purposes in this study, were taught by one faculty using the same content and exams, one can assume with high level of certainty that all other variables were controlled 
and the only thing different was the cultural environment of students. So, the results provide a fair assessment of learning comparison across different groups and locations. Furthermore, the students in Tampa and Nassau were all working adults similar to students in Kingston and this provides another commonality among them.

It is concluded that students enrolled in the masters course GMP5017, offered at the Kingston cluster of Nova Southeastern University during the summer 2004 term, did show significant progress in student performance as measured by scores on the pre-test and post-test examinations. Furthermore, their performance as measured by objective final exam scores seems to be very similar to the performance of students online as well as those in Nassau and Tampa who completed their classes in 2003 and 2002 respectively. It is possible that the results of this study may be applicable to future offerings of the same course and/or to additional master's courses; however, specific inferences drawn from data generated from this study should be limited only to similar situations in which faculty members and students jointly work on gaining knowledge related to course learning objectives.

The Huizenga School continues to expand its distance education offerings, in particular, those that are offered through face-to-face format at offsite locations. It is recommended that the Huizenga School build on the results of this study by pursuing additional studies to assess comparative student performance under circumstances in which courses are offered through different sites and delivery modes. Furthermore, it is recommended that Huizenga School administer standardized tests for courses at different sites in Jamaica, Nassau and throughout the various sites in the United States that are taught by different faculty members to see how consistently students are achieving the stated course outcomes.

\section{Bibliography}

Bailey, Margaret, (2003). Introduction to Typical Jamaican Family. Retrieved on 12/28/2003 from: http://www.jamaicans.com/culture/intro/typical_family.htm.

Davidson, Marcia (2003). Jamaican Culture: An Overview. Retrieved on 122803 from: http://www.jamaicans.com/culture/intro/index.htm

Jamaica, (2003). Jamaica. Retrieved from the following URL on 12/282003. http://encarta.msn.com/encyclopedia 761561054/Jamaica.html.

MacFarland, Thomas W., (November, 2003). Students in Jamaica Evaluate Resources and Services of Nova Southeastern University Library, Research, and Information Technology Center. Summer Term 2003. Report 03-18. Research and Planning.

Mujtaba, B.; Hinds, R. M..; \& Oskal, C. (December 2004). Cultural Paradigms of Age Discrimination and Unearned Privileges. Journal of Business and Economic Research, Volume 2, Number 12.

Mujtaba, B., (2004). "Comparison of Learning Outcomes between Jamaican Students with Students in the United States and the Grand Bahamas in "Delivering Superior Customer Value" Course at the H. Wayne Huizenga School of Business and Entrepreneurship." Proceedings of The International College Teaching Methods \& Styles Conference. Reno, Nevada, USA. September 27-30. 
Mujtaba, B. (2003). Cross-Cultural Teaching Considerations with Adult Students in Jamaica. Manual prepared for Faculty Orientation at the Huizenga School of Nova Southeastern University.

Mujtaba, B. \& Mujtaba, L. (2004). "Creating a Healthy Learning Environment for Student Success in the Classroom." The Internet TESL Journal. Vol. X, No. 2, February 2004. The article can be retrieved via the following URL link: http://iteslj.org/ or: http://iteslj.org/Articles/MujtabaEnvironment.html.

Preziosi, R.; Barnes, B.; Rivers, E.; and Gooden, D., (2000). "The Impact of Ground-based vs. Electronic-based Instructions Modality and Learning Style Preference on Learning Achievement among Selected HRM Topics in an MBA Program." Proceedings of the Institute for Behavioral and Applied Management. November 2000, San Diego, CA.

\section{Biography:}

Bahaudin Mujtaba is an Assistant Professor of Human Resources and International Management. $\mathrm{He}$ is also serving as the Director of Institutional Relations, Planning, and Accreditation for Nova Southeastern University at the H. Wayne Huizenga School of Business and Entrepreneurship in Fort Lauderdale, Florida. Bahaudin has worked as an internal consultant, trainer, and teacher at Training Development Departments of Human Resources as well as retail management in the corporate arena for 16 years. He currently serves on the editorial review boards for the Society for Advancement of Management (SAM) Journal, Journal of Applied Management and Entrepreneurship (JAME), and others on ad hoc basis. Academically, Bahaudin has been teaching graduate business courses both nationally and internationally (Bahamas, Jamaica and Brazil) since 1996. Bahaudin's undergraduate degree is from the University of Central Florida. His MBA and DBA degrees are from Nova Southeastern University. His current research and focus are concentrated in the areas of diversity in higher education as well as learning outcomes assessment. 